\title{
Strateške dileme in alternativne usmeritve neprofitnih športnih klubov
}

\author{
Igor Ivašković* \\ Ekonomska fakulteta, Kardeljeva ploščad 17, 1000, Slovenija \\ igor.ivaskovic@ef.uni-lj.si
}

\begin{abstract}
Povzetek:
Raziskovalno vprašanje (RV): Katere so ključne strateške odločitve, o katerih odločajo vodstva športnih klubov in katere strateške alternative so jim na voljo?

Namen: Namen prispevka je pomagati vodstvom neprofitnih športnih klubov pri identifikaciji ključnih strateških dilem in strateških alternativ, ki so na voljo tem organizacijam.

Metoda: Uporabljena je analiza ekonomskih, političnih in drugih družbenih dejavnikov, ki so vplivali na športno industrijo na obravnavanem področju. Nato so s pregledom literature s področja poslovnih ved pojasnjene posebnosti procesa produkcije in identifikacijo treh ključnih strateških dilem.

Rezultati: Ugotovljene tri dileme so: a) fokus na tekmovalnih rezultatih ali na razvoju lokalne skupnosti, b) hitrejše doseganje ciljev ali manjša stopnja tveganja, c) zmanjševanje stroškov ali rast organizacije. Na podlagi različnih kombinacij članek na koncu predstavi pet temeljnih alternativnih usmeritev, in sicer: a) strateški fokus na športnih rezultatih, b) strategija anorganske rasti, c) strategija organske rasti, č) strategija razvoja okolja ter d) strategija povečevanja rezerv oz. preživetja.

Organizacija: Študija ponuja novo klasifikacijo strategij neprofitnih športnih klubov.

Družba: Študija poudarja pomen odnosa med športnimi klubi in lokalno skupnostjo in prikazuje, kako se ta odnos spreminja glede na izbrano strategijo.

Originalnost: Nova klasifikacija strateških alternativ. Ena prvih raziskav o ključnih poslovnih odločitvah neprofitnih športnih klubov v Jugovzhodni Evropi.

Omejitve/nadaljnje raziskovanje: Priporočljive so nadaljnje raziskave med športnimi klubi skozi daljše časovno obdobje, v različnih okoljih in v različnih športnih panogah.
\end{abstract}

Ključne besede: športni klubi, neprofitne organizacije, tranzicija, strategije, poslovno odločanje.

\section{Uvod}

$\mathrm{V}$ okolju $\mathrm{z}$ omejenimi viri in konkurenco med organizacijami vsaka izmed njih teži $\mathrm{k}$ vzpostavitvi določene lastnosti, ki ji bo omogočila konkurenčno prednost. Menedžment je v tem kontekstu proces, ki poteka prek več funkcij, pri čemer je planiranje zagotovo ena najpomembnejših, še posebej to velja $\mathrm{v}$ primeru neprofitnih športnih organizacij (Škorić in Bartoluci, 2014, str. 120). Strateško planiranje je pri tem usmerjeno v ključne dejavnike uspešnosti, za katere vodstvo predvideva, da bodo dolgoročno pomembno vplivali na organizacijo, oz. smatra, da bodo omogočili njeno doseganje in ohranjanje konkurenčne prednosti (Porter, 1987, str. 2). Pri tem so v specifičnem položaju neprofitni športni klubi v 
(post)tranzicijskih državah, saj morajo kot storitvene organizacije, ki so tesneje vezane na lokalno okolje, in zaradi posebnostih produkcijskega procesa nekoliko več energije vlagati tudi prilagajanju lokalnem družbenem kontekstu (Ivašković, 2020, str. 668). Obenem vsaj formalna neprofitnost teh klubov implicira širši spekter potencialih temeljnih razlogov obstoja in posledično tudi več potencialnih strateških usmeritev, med katerimi njihova vodstva lahko izbirajo (Ivašković, 2019a, str. 159).

Namen prispevka je spodbuditi razpravo o načinu delovanja športnih klubov v Sloveniji in državah s podobnim zgodovinskim kontekstom, in sicer z identifikacijo strateških alternativ, ki so na voljo športnim klubom v (post)tranzicijskih evropskih državah, kateri delujejo na področju ekipnih športov in še vedno ohranjajo status neprofitnih organizacij. V prvem delu so pojasnjene posebnosti procesa produkcije športnih klubov in širši družbeni kontekst, v katerem obravnavane organizacije delujejo. Nato so s pregledom literature s področja strateškega menedžmenta identificirane tri ključne dileme, s katerimi se vodstva teh organizacij soočajo, na kar so na podlagi različnih kombinacij odločitev predstavljene opcije, ki se v obliki alternativnih strateških usmeritev ponujajo tem športnim klubom.

\section{Teoretična izhodišča}

\subsection{Posebnosti produkcijskega procesa}

Športni klubi se primarno ukvarjajo z izvajanjem športne dejavnosti v obliki aktivne udeležbe na športnih tekmovanjih. Njihov temeljni produkt je torej storitev, ki poleg splošno znanih značilnosti (neločljivosti produkcije od porabe, nezmožnosti skladiščenja itd.) implicira tudi nujnost sodelovanja drugega kluba, ki v športnem smislu predstavlja nasprotnika, v poslovnem pa partnerja. Povprečni športni navdušenec bo po vsej verjetnosti brez prevelikega razmišljanja kot konkurenco določenega športnega kluba navedel njegove športne tekmece iz iste panoge. Tako bo na primer za nogometni klub Real iz Madrida največji konkurent nogometni klub Barcelona, za košarkarski klub Olimpija iz Ljubljane pa bo to košarkarski klub Krka iz Novega mesta ipd. Res je, omenjeni klubi so športni konkurenti, ki konkurirajo za športne lovorike v istih tekmovanjih, posledično tudi za denarne nagrade in posredno za povečanje interesa pri potencialnih sponzorjih. Navedeni klubi si konkurirajo tudi za kader oziroma za vrhunske športnike, ki jih želijo pritegniti v svoje vrste. Vendar istočasno klubi v določenem tekmovanju ne bi mogli poslovati, v kolikor ne bi obstajali njihovi športni tekmeci. Možnost uresničevanja poslanstva športnega kluba je torej odvisna od obstoja športnih konkurentov $\mathrm{v}$ okviru organiziranih ligaških in pokalnih tekmovanj. Slednja so organizirana pod okriljem krovnih organizacij, najpogosteje so to zveze klubov. Športni klubi se torej prostovoljno združujejo v zveze ravno s svojimi športnimi konkurenti, proti katerim nato tekmujejo na športnih igriščih. $\mathrm{V}$ tem primeru lahko torej govorimo o specifičnem konkurenčno-partnerskem odnosu. Ravno ta ambivalentnost je najpomembnejša lastnost klubskih športnih tekmovanj. Poleg tega pa imajo seveda klubi tudi konkurenčne organizacije v klasičnem smislu, pri čemer gre večinoma za športne klube iz drugih športnih panog. 
Produkcijski proces športnih klubov je le na videz enostaven. Klubi morajo namreč najprej sestaviti tekmovalno ekipo, ki se neposredno udeležuje športnih tekmovanj. Na slednjih poskušajo doseči čim boljši rezultat. V kolikor je posamezen klub pri tem uspešen, ima večje možnosti za spodbuditev interesa javnosti. S tem bo posledično povečal število tako fizično prisotnih gledalcev na tekmah kot tistih, ki klub spremljajo prek različnih medijev. Slednje ima poleg neposrednega finančnega učinka še bolj pomemben posredni učinek. Večji interes javnosti običajno poveča tudi interes vlagateljev, kar klubu omogoči pridobivanje novih virov sredstev in posledično ustvarjanje večjih letnih proračunov za naslednjo tekmovalno sezono. To omogoča sestavo še bolj kakovostne ekipe in omogoča pozitivno spiralo učinkov v produkcijskem procesu. V nasprotnem primeru, ob eventualnih športnih neuspehih, pa klub lahko zaide $\mathrm{v}$ tok negativnih posledic. $\mathrm{V}$ tem kontekstu je potrebno opomniti na evropski sistem športnih tekmovanj, ki za razliko od profesionalnih tekmovanj na severnoameriški celini implicira višjo stopnjo tveganja za vodstva klubov. Eventualni slabši rezultat v določeni tekmovalni sezoni in posledični izpad iz trenutnega ranga tekmovanja namreč pomeni, da bo klub potreboval najmanj eno leto za vrnitev v prejšnji rang tekmovanja.

$\mathrm{Na}$ osnovi modela produkcijskega procesa, ki je bil razvit na primeru italijanskih nogometnih klubov, so Kern, Schwarzmann in Wiedenegger (2012, str. 180-182) predlagali, da se ocenjevanje uspešnosti tekmovalnih športnih klubov izvaja na treh ravneh, in sicer na ravni menedžmenta, športnega rezultata in tržne učinkovitosti.

Iz modela je razvidno, da je s strateškega vidika najpomembnejše dolgoročno zagotavljanje finančnih sredstev, ki omogoča delovanje kluba, predvsem pa olajšuje proces strateškega planiranja. V tem pogledu se športni klubi ne razlikujejo bistveno od večine ostalih organizacij, vendar pa dejstvo kompleksnosti športa kot družbene dejavnosti in povezanih številnih nepopolnosti trga vpliva na to, da same športne organizacije običajno ne morejo delovati povsem brez vpletanja javnega sektorja. To implicira že sama ekonomska teorija, saj je korist od športa tako zasebna kot javna, zato je razumno, da tako zasebni kot javni sektor sorazmerno upravičita koristi od športnih dejavnosti. Downward, Dawson in Dejonghe (2009, str. 196) so dokazali, da šport ni potrebno povsem prepustiti trgu, saj se pojavljajo tako monopolna stanja, kot eksternalije, prihaja tudi do nepopolnih informacij itd. Jasno je, da bi v primeru popolnega prepuščanja trgu potencialnim športnikom v komercialno manj zanimivih panogah bistveno zmanjšali možnost ukvarjanja s športom, kar pa je v nasprotju s samim poslanstvom športnih organizacij. Po navedbah Sveta Evrope (2021) je to omogočanje enakih pravic vsakemu pri možnostih ukvarjanja s športom in dostopu do športa. Posledično je razumljivo, da se država oziroma enote lokalne samouprave postavljajo v vlogo agentov, ki poskušajo s financiranjem določenih športnih organizacij zmanjšati vpliv tržnih nepopolnosti. 


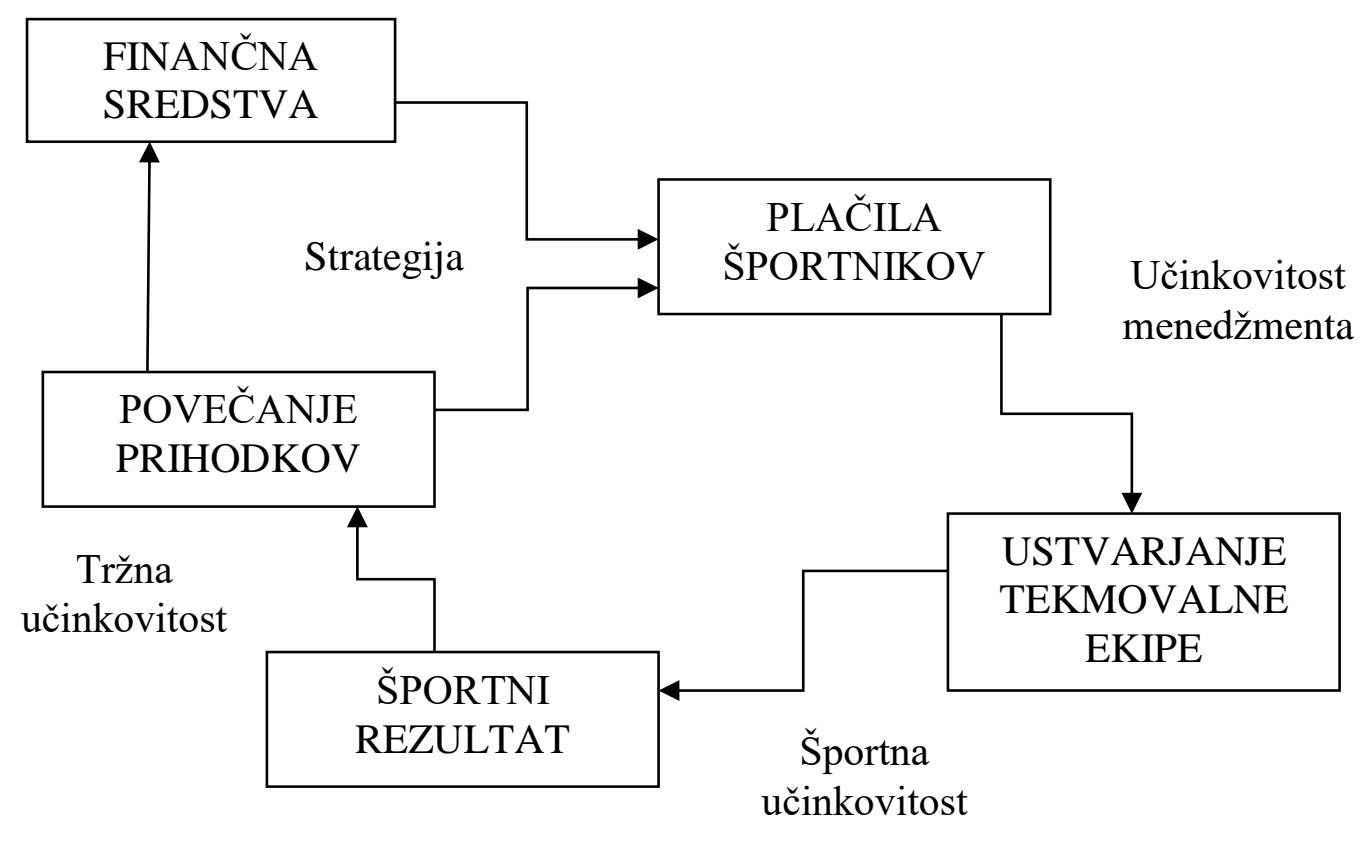

Slika 1. Tri ravni učinkovitosti v produkcijskem procesu športnih klubov, po Kern, Schwarzmann, \& Wiedenegger, 2012, Sport, Business and Management: An International Journal, 2(3), str. 181.

Športne organizacije imajo v kontekstu evropskega sistema financiranja več potencialnih virov prihodkov, in sicer članarine, prodaja vstopnic, oglaševanje in sponzorstva, televizijske in ostale medijske pravice, prihodke s strani krovnih organizacij oziroma zvez, prodaja ostalih artiklov, prihodke s strani pravnih subjektov javnega prava in drugo (Evropska komisija, 2007, str. 26). Javne institucije financirajo športne klube tako z direktnimi donacijami iz državnih, pokrajinskih ali občinskih proračunov, deležem sredstev, pridobljenih z igrami na srečo, $\mathrm{s}$ pomočjo posebnih davščin oziroma $z$ zmanjšanjem davčne stopnje samim športnim organizacijam, z oddajanjem športne infrastrukture pod tržno ceno in podobno. Raziskave na področju financiranja športa potrjujejo, da je delež javnih sredstev v skupnem financiranju športa še vedno nekoliko večji v (post)tranzicijskih državah in se ni bistveno spremenil od leta 1990 (Andreff, 2006, str. 272-273; Škorić, Bartoluci, \& Čustonja, 2012, str. 183; Andreff, Dutoya, \& Montel, 2009, str. 1). Izredno pomemben posreden vir prihodkov za večino športnih klubov predstavlja tudi volontersko delo. V državah EU naj bi po nekaterih ocenah že v letu 2006 znotraj približno 700.000 športnih klubov delovalo okoli 10 milijonov volonterjev (Arnaut, 2006, str. 19). Najnovejše raziskave kažejo, da se strukture prihodkov športnih klubov niso bistveno spremenile, obstajajo pa pomembne razlike med prihodki amaterskih klubov in tistih z višjo stopnjo profesionalizacije ter med športnimi klubi v različnih panogah. Višja stopnja profesionalizacije namreč implicira večji delež sredstev iz zasebnih virov, medtem ko največ sponzorstev uspeta pritegniti nogometna in košarkarska panoga (Sanchez, Barajas, \& Sanchez-Fernandez, 2019, str. 328-329; Ivašković, 2018, str. 190-191; Barget \& ChavinierRela, 2017, str. 9-13). 


\section{2 (Post)tranzicijske implikacije}

Športni klubi v (post)tranzicijski jugovzhodni Evropi so se že v času centralno-planske gospodarske ureditve, v kateri je prevladoval koncept državne oziroma družbene lastnine, udeleževali mednarodnih tekmovanj, kjer so se soočali s športno konkurenco iz držav s tržno ekonomijo. Seveda so to možnost imeli le najboljši klubi, ki so imeli dostop do najboljših kadrov in največjega obsega finančnih sredstev. $Z$ ambicijo po enakopravnem konkuriranju profitnim klubom so neprofitne organizacije morale zagotoviti zadosten obseg sredstev, ki pa ga niso mogle dobiti iz zasebnih virov. Glavne vire financiranja športne dejavnosti so predstavljala podjetja v »družbeni« oziroma državni lasti, v katerih so se ključne odločitve sprejemale v skladu s filozofijo političnega sistema. Slednji je istočasno zagotavljal pravni okvir, ki je onemogočal odliv športnih talentov v tujino, kar je vsaj v določeni meri omogočalo uspešno tekmovanje na nekaterih športnih področjih. Institut družbene lastnine je impliciral izjemno velik vpliv državnih oblasti, ki so izbirale klubske paradne konje za zastopanje države navzven. To je po eni strani omejevalo konkurenco navznoter, saj so bili le izbranci deležni večje pomoči s strani državnih podjetij, istočasno pa je tedanja deležniška struktura v športnih klubih implicirala tudi zasledovanje neprofitnih motivov. Športni rezultat je namreč služil kot sredstvo promocije države in posredno državnega sistema navzven. Obenem so bili vsi klubi dolžni vlagati v razvoj mladinskih pogonov, saj je bilo za klube tako s pravnega kot s finančnega vidika nemogoče angažirati športne kadre izven države.

S spremembo politično-gospodarskega sistema je nastopilo tranzicijsko obdobje, v katerem so se klubi soočili ne le s postopno liberalizacijo trga športne delovne sile, temveč tudi s spremembo strukture interesnih skupin, ki so bile vpete v delovanje klubov. To je bila posledica postopne privatizacije večine podjetij, ki so do tedaj sodelovala pri financiranju športnih klubov. Začetek zasledovanja profitnega motiva lastnikov podjetij je postopoma privedel tudi do racionalizacije vlaganj $\mathrm{v}$ šport. Kljub temu so klubi večinoma ohranili neprofitno obliko delovanja. Klube v posameznih državah na to silijo krovne športne organizacije, v drugih pa se za tem skriva poskus zmanjšanja tveganja za prelivanje učinkov neuspeha s športnega na poslovno področje. Skrb za razvoj vrhunskega športa se je posledično z relacije kubi - politični (državni ali lokalni) odločevalci prenesel na odnos med klubskimi vodstvi in zastopniki zasebnih interesov in njihovega kapitala. To je povečalo pritiske na klube v smeri iskanja čim boljših kadrov in vse bolj tudi zasledovanja modela uspešnosti, ki je prevladoval pri športnih klubih iz držav z neprekinjeno tradicijo tržnega gospodarstva.

Drugi institucionalni dejavnik, ki vpliva na posebnost klubov v (post)tranzicijskih državah, je sistem evropskih ligaških tekmovanj. Klubi se morajo namreč za sodelovanje v najkakovostnejših tekmovanjih običajno kvalificirati prek nacionalnih tekmovanj (Fort, 2000, str. 431-433). Posledično najuspešnejši športni klubi iz jugovzhodne Evrope hkrati sodelujejo $\mathrm{v}$ evropskih tekmovanjih s pretežno profitno usmerjenimi tekmeci in v domačih državnih ligah z neprofitnimi športnimi konkurenti. Raziskave $\mathrm{z}$ drugih področij nakazujejo na to, da se vodstva neprofitnih organizacij pogosto začnejo obnašati bolj stroškovno učinkovito in začnejo zasledovati poslovno logiko v primerih, ko so njihove organizacije soočene s konkurenco, ki 
jih vodi profitni motiv (Ko in Liu, 2020, str. 8). Analogno bi lahko pričakovali, da bo sodelovanje $\mathrm{v}$ mednarodnih tekmovanjih in proces profesionalizacije pri neprofitnih športnih klubih pospešil proces prilagajanja $v$ smeri načina poslovanja profitnih organizacij.

Prelomnico za evropske športne klube in posledično tudi za preučevane neprofitne klube iz (post)tranzicijske Evrope je predstavljalo sprejetje t. i. Bosmanovega pravila, ki je prispevalo k liberalizaciji trga športne delovne sile. To je z omogočanjem lažjega prehajanja športnikov med klubi iz različnih držav povečalo pogajalsko moč vrhunskim poklicnim športnikom, dodalo novo dimenzijo pri menedžmentu človeških virov (HRM) in povečalo konkurenčno prednost finančno močnejših klubov. Istočasno je to povzročilo dodatne težave finančno šibkejšim klubom iz (post)tranzicijskih držav, ki so morali z omejenimi sredstvi in ob dejstvu lažjega odhoda talentiranih mladih športnikov ustvariti pogoje za doseganje zadovoljivih športnih rezultatov, s katerimi bi spodbudili pozitivne učinke v lastnem produkcijskem procesu. Proces tranzicije iz centralno-planskega $\mathrm{v}$ tržno gospodarstvo ter posledični proces liberalizacije trga športne delovne sile sta med klubi (post)tranzicijske Evrope povzročila še nekoliko večje razslojevanje glede virov financiranja. Tisti klubi, ki so želeli ostati konkurenčni tujim profitnim klubom, so ob zmanjšanju državne vloge morali poiskati pomoč zasebnih investitorjev, kar je vplivalo na celo vrsto sprememb $\mathrm{v}$ poslovanju klubov $\mathrm{s}$ ciljem zadovoljevanja interesov zasebnih sponzorjev.

Produkcijski proces športnih klubov v (post)tranzicijsko-neprofitnem kontekstu torej poleg posebnosti, ki so značilne za vse športne organizacije, kot je na primer dejstvo krajše delovne dobe športnikov in razvit trg vrhunskih športnikov, zaznamujejo tudi kompleksni HRM sistemi in dvojnost organizacijske strukture. HRM procesi se namreč razlikujejo glede na to, ali se nanašajo na administrativno-vodstveno osebje ali na športni kader (Ivašković, 2018, str. 195). Pri tem se drugi del HRM procesov lahko razdeli še na dva podsegmenta, in sicer tistega, ki se nanaša na športni kader, ki ga klubi pridobivajo na trgu, drugi del pa predstavlja HRM v kontekstu razvoja lastnih kadrov skozi otroške oziroma mladinske ekipe. Dvojnost organizacijske strukture je posledica kombiniranja profesionalnega in amaterskega dela znotraj iste organizacije. Slovenska zakonodaja na področju športa sicer ne opredeljuje ločnice med profesionalnimi in amaterskimi klubi, na drugi strani pa hrvaški Zakon o sportu (2019) jasno navaja pogoje profesionalnosti. ${ }^{1}$ Potrebno je poudariti, da profesionalnost in neprofitnost nikakor nista nujno povezana pojma, saj je vsak klub ne glede na svojo potencialno neprofitno naravnanost še vedno lahko tudi profesionalni klub. Istočasno pa je lahko znotraj kluba, ki izpolnjuje pogoje za status profesionalnega, tudi ogromen del organizacije, ki nima profesionalne narave, v katerih so angažirana in se trošijo sredstva za povsem amatersko dejavnost. Na primer, določeni klubi imajo znotraj organizacije tudi mladinski pogon ali drugo člansko ekipo, celo posebne oddelke, ki se ukvarjajo z volontersko dejavnostjo spodbujanja

\footnotetext{
${ }^{1} \mathrm{~V}$ svojem 24. členu namreč omenjeni zakon pravi, da so profesionalni športni klubi tisti, ki imajo v tekoči tekmovalni sezoni med prijavljenimi športniki v članski vrsti več kot 50 \% profesionalnih športnikov. Obenem 8 . člen istega zakona opredeljuje kot profesionalnega športnika tistega, ki ima sklenjeno pogodbo o profesionalnem igranju za klub, ima sklenjeno pogodbo o zaposlitvi s klubom, ali pa opravlja samostojno športno dejavnost z udeležbo na športnih tekmovanjih.
} 
pozitivnih družbenih procesov $\mathrm{v}$ lokalnem okolju, in ki delujejo povsem na amaterskih principih. Kljub temu da je njihova prva članska ekipa profesionalizirana, obstaja možnost, da opravijo več amaterske dejavnosti, kot jo opravijo ostali deklarirani amaterski klubi. Prav takšna dvojnost oziroma kombinacija profesionalnega in amaterskega dela organizacije je značilna za klube iz evropskih (post)tranzicijskih držav.

\subsection{Strateške dileme}

V literaturi obstaja več tipologij strategij (Porter, 1985, str. 11; Tan \& Litschert, 1994, str. 1213; Pučko, 1999, str. 176), a se z ozirom na navedene posebnosti klubov v ekipnih športnih panogah (predvsem konkurenčno-partnerski odnos med klubi in pravila tekmovanja, ki determinirajo končno obliko produkta, ter neprofitni status, ki omogoča veliko širši spekter temeljnega cilja obstoja) pri klubih iz iste športne panoge zdi najbolj smiselno razlikovanje glede na pristop k produkcijskemu procesu. Ta je sicer v svoji osnovi enak vsem klubom, a imajo vodstva $v$ opredeljenih kritičnih točkah možnost sprejemanja različnih odločitev. V kateri točki produkcijskega procesa športnih klubov prihaja do ključnih strateških odločitev, sta opozorila že Baroncelli in Lago (2006, str. 20-22), medtem ko so to empirično potrdili Kern, Schwarzmann in Wiedenegger (2012, str. 177-178). Slednji so namreč na primeru profitnih nogometnih klubov opazili, da se pri vodstvih športnih klubov pogosto pojavlja dilema, kako in v kolikšnem deležu naj se porabijo klubska letna proračunska sredstva. $\mathrm{S}$ to dilemo se ukvarjajo tako manj kot bolj uspešni klubi. Ravno iz procesa delitve letnega proračuna kluba, v kolikor ga spremljamo skozi več let, v največji meri lahko razberemo dejanske strategije, ki jih posamezen klub zasleduje. Omenjeni avtorji so pri tem opozorili na potencialni konflikt, do katerega lahko pride med tistimi, ki eventualni presežek prihodkov nad odhodki želijo usmeriti v razvoj športne infrastrukture, in na drugi strani tistimi, ki bi se raje osredotočili na pridobivanje novega športnega kadra $z$ večjo tržno vrednostjo ter večjim športnim potencialom od obstoječega. Pri tem lahko športne klube razdelimo na tiste, ki zasledujejo vzdržno oziroma stabilno strategijo, in tiste, ki zasledujejo strategijo hitrega doseganja vrhunskih športnih rezultatov. Medtem ko prvi večino svojih finančnih presežkov vlagajo v razvoj infrastrukture in razvoj lokalne baze mladih športnikov, se drugi usmerjajo na takojšnje vlaganje večine finančnih presežkov v angažiranje novih športnikov, ki so trenutno bližje vrhuncu svojih fizičnih in taktičnih sposobnosti ter jih je mogoče z razpoložljivimi finančnimi sredstvi pridobiti na trgu. S slednjimi lahko namreč v krajšem času uresničijo ambicije po vrhunskem športnem dosežku. Ta strategija omogoča hitrejšo rast oziroma pospešuje dinamiko pozitivnih spiralnih učinkov, vendar je obenem zaradi večjih finančnih vložkov tudi bolj tvegana od t. i. stabilne strategije. S tem se dotaknemo ključnega momenta v produkcijskem procesu športnih klubov, in sicer problema izbire strategije oziroma strateškega fokusa klubskega vodstva, ki se manifestira pri procesu delitve proračuna, kateri je determiniran s strukturo lastnikov in njihovih interesov. $\mathrm{Z}$ ozirom na to in stopnjo agresivnosti strategije, ki jo opredeljujeta Tan in Litschert (1994, str. 4), lahko izpostavimo tri ključne strateške dileme neprofitnih športnih klubov:

- VSEBINA - V kolikšni meri poudarjati pomembnost vrhunskih tekmovalnih rezultatov (intenzivno športno delovanje) na račun želje po razvoju lokalne skupnosti (ekstenzivno 
delovanje)? Gre za temeljno dilemo športnih klubov, ki je posledica združevanja pojmov športa, ki implicira tekmovalnost, in kluba, ki predstavlja organizacijo, vpeto v lokalno skupnost. Čeprav se morda na prvi pogled oba smotra delovanja športnega kluba ne zdita izključujoča, se vodstvo prej ali slej mora opredeliti, ali bo večji poudarek dalo na vključevanju domačega prebivalstva tako članov kot nečlanov kluba v klubske aktivnosti, ali pa bo povsem internacionaliziralo svojo dejavnost in bo poskušalo klub z najboljšimi resursi, ki se ponujajo na mednarodnih trgih, pripeljati do tekmovanj na najvišji državni, evropski in svetovni kakovostni ravni. Gre torej za opredeljevanje temeljnega cilja in s tem poslanstva organizacije.

- ČAS - V kolikšni meri zahtevati hitre rezultate (sprejemati večje tveganje) nasproti dolgoročnemu delu in manjšemu tveganju? To je klasična dilema, ki se pojavlja pri vseh investicijskih odločitvah. Gre za odločitev vlagatelja, kdaj želi realizirati donos od investicije. Krajši rok povračila vloženega in pričakovana visoka donosnost seveda predstavljata večjo korist za investitorja. Vendar to običajno implicira tudi višjo stopnjo tveganja. V primeru športnih klubov gre v tem kontekstu običajno za odločitev vodstva o tem, kako hitre pozitivne spiralne učinke želi in koliko je pri tem pripravljeno tvegati. Najhitrejši spiralni učinki se ponujajo pri zasledovanju t. i. strategije anorganske rasti (velik delež proračuna za zunanjo rast in številne dejavnosti na mednarodnih trgih), a je to tudi strategija z najvišjo stopnjo tveganja.

- RAST - V kolikšni meri zasledovati cilj rasti nasproti ambiciji po optimizaciji stroškov? Ta razmejitev odraža dve dimenziji Tanove in Litschertove (1994, str. 3-5) delitve strategij, in sicer stopnji napadalnosti in proaktivnosti. Bolj napadalna in proaktivna vodstva namreč poskušajo izboljšati in povečati obseg delovanja organizacije, medtem ko tista $\mathrm{z}$ manjšo stopnjo proaktivnosti zavirajo spremembe in se ne spuščajo v nove projekte. Organizacija lahko raste na več načinov. Lahko namreč povečuje svoje članstvo ali povečuje obseg organizacijskih dejavnosti, vendar pa tudi povečevanje obsega organizacijske aktive predstavlja organizacijsko rast. Ambicija po zmanjševanju stroškov ni povsem v nasprotju s slednjo, vendar je običajno v neskladju s klasičnim razumevanjem rasti organizacije, ki se nanaša na povečevanje članstva in obsega dejavnosti. Tudi v primeru športnih klubov se vodstva soočajo z dilemo povečevanja članstva in posledično povečevanja aktivnosti na eni in konservativno politiko na drugi strani. Rast organizacije predstavlja potencial tudi za večje prihodke, vendar je $\mathrm{v}$ ta namen najprej potrebno vložiti določen obseg sredstev. To vključuje vlaganje v klubsko infrastrukturo, $v$ trženjske dejavnosti za privabljanje mladih, investicije $\mathrm{v}$ trenerski in administrativni kader itd.

\section{Metoda}

Na temelju analize ekonomskih, političnih in drugih družbenih dejavnikov, ki so vplivali na športno industrijo na obravnavanem področju, in pojasnjene posebnosti procesa produkcije ter identifikacije treh ključnih strateških dilem smo najprej želeli razviti alternativne strateške možnosti, ki so na voljo športnim klubom. Pri tem smo kombinirali dihotomije pri treh 
strateških dilemah. Nato smo z željo preverjanja, v kolikšni meri klubi dejansko zasledujejo posamezno strategijo, izvedli raziskavo med 73 košarkarskimi klubi iz Bosne in Hercegovine (BIH), Hrvaške, Slovenije in Srbije. Ta vzorec predstavlja 29,3 \% od skupnega števila (249) košarkarskih klubov, ki so v tem času obstajali v predmetnih štirih državah v vseh kakovostnih rangih tekmovanj pod okriljem nacionalnih panožnih zvez. 27 izmed 73 klubov je sodelovalo $\mathrm{v}$ prvih ligah (9 izmed teh tudi v mednarodni ABA ligi), $31 \mathrm{v}$ drugih in $15 \mathrm{v}$ nižjih. Podatke smo pridobili s strani članov uprave ali izvršnega direktorja v posameznem klubu. Pridobljeni podatki so bili obdelani s pomočjo programa SPSS, pri čemer sta bili opravljeni deskriptivna statistična analiza (izračuni povprečij in razlik med skupinami) ter korelacijska analiza.

\section{Rezultati in razprava}

\subsection{Alternativne usmeritve}

Na osnovi do sedaj navedenega lahko razvijemo alternativne strateške možnosti, ki so na voljo vodstvom športnih klubov. Pri tem se zaradi širšega manevrskega prostora, ki ga omogoča neprofitno poslanstvo, pojavlja nekoliko širši spekter strateških ciljev, ki pa se glede same vsebine odločanja ne razlikuje bistveno od tistega v profitnih športnih klubih. Tudi neprofitni klubi se namreč soočajo z dilemo razdelitve letnega proračuna. Razumljivo je tudi, da želijo slednjega tudi vodstva neprofitnih klubov povečati, saj večji obseg sredstev ob predpostavki ceteris paribus omogoča lažje uresničevanje njihovega poslanstva. Čeprav kombiniranje treh odločitev omogoča hipotetično osem različnih kombinacij, se pred ključnimi odločevalci v neprofitnih športnih klubih $\mathrm{v}$ praksi ponuja pet različnih možnosti usmerjanja denarnih sredstev, in sicer: a) v amaterski del kluba, b) v profesionalni kader, c) v klubsko infrastrukturo in izboljšanje notranjih organizacijskih procesov, d) $\mathrm{v}$ lokalno skupnost in e) $\mathrm{v}$ povečanje klubskih rezerv. V odvisnosti od tega, v kateri element vodstvo kluba največ vlaga, se lahko oblikuje pet temeljnih strateških alternativ. Pri tem je potrebno še enkrat poudariti, da se klubi glede treh strateških dilem redko odločajo za ekstremne odločitve, ki bi povsem izključile določen cilj, vendar se bolj ali manj nagibajo k določeni strateški usmeritvi. Posledično se tudi opredeljene strateške alternative neprofitnih športnih klubov v praksi skoraj nikoli ne pojavljajo v čistih oblikah. Vodstva se namreč lahko odločijo, da klubska proračunska sredstva porazdelijo tako med lokalno skupnost, kot tudi za povečevanje članstva, vlaganje v obstoječo ekipo in pridobivanje novih, bolj kakovostnih športnikov na mednarodnih trgih. Ne nazadnje je dejstvo, da so učinki teh odločitev pogosto tudi povezani, saj na primer vlaganje v lokalno skupnost posredno lahko privede do povečevanja baze mladih športnikov iz lokalnega okolja. Tabela 1 prikazuje, v kakšnih pogojih (glede na razreševanje treh temeljnih dilem) se pojavlja pet opredeljenih strateških alternativ. 
Tabela 1. Strateške alternative glede na ključne strateške odločitve

\begin{tabular}{lcc}
\hline \multicolumn{1}{c}{ Fokus } & Športni rezultat & Lokalna skupnost \\
\hline $\begin{array}{l}\text { Hitri rezultati in } \\
\text { zmanjševanje stroškov }\end{array}$ & $\begin{array}{c}\text { Fokus na športnih rezultatih ali } \\
\text { strategija anorganske rasti }\end{array}$ & Strategija povečevanja rezerv \\
Hitri rezultati in rast & Strategija anorganske rasti & Strategija razvoja okolja \\
$\begin{array}{l}\text { Dolgoročno delo (manjše } \\
\text { tveganje) in zmanjševanje } \\
\text { stroškov }\end{array}$ & Fokus na športnih rezultatih & $\begin{array}{r}\text { Strategija preživetja ali } \\
\text { strategija razvoja okolja }\end{array}$ \\
$\begin{array}{l}\text { Dolgoročno delo (manjše } \\
\text { tveganje) in rast }\end{array}$ & Strategija organske rasti & Strategija organske rasti ali strategija \\
\end{tabular}

(1) Strateški fokus na razvoju lokalnega okolja. To strateško usmeritev zasledujejo klubi, ki so močno nagnjeni $\mathrm{k}$ zasledovanju interesov lokalne skupnosti na račun doseganja vrhunskega športnega rezultata. Gre za zmerno defenzivno strategijo, pri kateri običajno ni pritiskov za doseganje hitrih rezultatov, medtem ko je rast nasproti zmanjševanju stroškov nekoliko manj pomembna komponenta. V stvarnosti se sicer pogosteje pojavlja pri tistih klubih, ki rastejo, saj se klubi, ki se ukvarjajo s težavo lastnega preživetja, težje osredotočajo na razvoj okolja. Klubi, ki dajejo poudarek tej strateški usmeritvi, večino svojih finančnih presežkov vlagajo neposredno nazaj v lokalno okolje oziroma v lokalno skupnost, ki ni nujno včlanjena v klub. Pogosto je to posledica pričakovanj lokalne javnosti, saj naj bi za neprofitne organizacije, posebej pa športne klube, ki imajo močno lokalno oziroma regionalno komponento delovanja, ravno ožja skupnost predstavljala primarni krog uporabnikov klubskih storitev. Poznamo več različnih vrst vlaganj v lokalno okolje, na primer vlaganja $v$ športno infrastrukturo ali organizacija različnih športnih prireditev. Vse te aktivnosti naj bi vplivale na dvig ravni konkretne športne organizacije in povečale stopnjo vključenosti lokalne skupnosti $\mathrm{v}$ delo kluba, kar naj bi bilo $\mathrm{v}$ skladu z zasledovanjem trajnostne strategije. Poslanstvo takšnih organizacij je povečevanje priljubljenosti športa nasploh (zato običajno niso omejene le na eno športno dejavnost), rast števila rekreativnih športnikov in posledično boljše psihofizično stanje članov lokalne skupnosti, znotraj katere klub deluje. Čeprav jih širša javnost običajno ne zaznava, saj ne polnijo stolpce športnih rubrik v dominantnih medijih, je organizacij s takšnim strateškim fokusom relativno veliko.

(2) Strateški fokus na športnih rezultatih. Nekatera klubska vodstva postavljajo vrhunske športne rezultate kot končni cilj delovanja športnega kluba. Ključnega pomena pri tem je torej odločitev zasledovanja strategije vrhunskega rezultata na račun razvoja lokalnega okolja. Takšni klubi običajno ne stremijo k rasti, in sicer niti z vidika povečevanja klubskega članstva niti z vidika povečevanja obsega dejavnosti. Rast v teh klubih se običajno odraža le preko povečevanja vrednosti sredstev v aktivi bilance. Njihova vodstva običajno niso naklonjena pretiranemu tveganju, zato je za njih bolj značilen dolgoročni cikel, a to ni nujni pogoj, saj je odvisen od dolgoročnosti odnosov z glavnimi viri denarnih sredstev. Vsekakor pa je vrhunski športni rezultat predpostavljen cilj vsem drugim in predstavlja prestiž, s 
katerim se lahko poistovetijo vsi deležniki, vključeni v delovanje kluba. Med neprofitnimi klubi izstopajo tisti, ki imajo višjo stopnjo profesionalizacije in tekmujejo v mednarodnih tekmovanjih skupaj z profitnimi klubi. Ti običajno večino svojih presežkov namenijo za investicije $\mathrm{v}$ izboljšave notranjih procesov, infrastrukture ter $\mathrm{v}$ športni kader. To naj bi povečalo konkurenčnost klubske ekipe in možnost doseganja vrhunskega športnega rezultata. Zaradi posebnosti evropskih ligaških tekmovanj oziroma zaradi odprtega sistema, v katerem boljši klubi napredujejo, slabši pa nazadujejo v nižje kakovostne range tekmovanja, si klubi s fokusom na doseganje vrhunskih športnih rezultatov kontinuirano skozi daljše časovno obdobje ne morejo privoščiti slabših tekmovalnih sezon. Tveganje za slednje zmanjšujejo tako, da med posameznimi sezonami izboljšujejo notranje procese in infrastrukturo kluba, kar deluje privlačno za športnike. Obenem zadržijo jedro dosedanje ekipe, kar običajno vključuje trenerja in ključne nosilce igre ter prispeva k izboljšanju notranjih procesov zaradi učinkov krivulje učenja. Ostale športnike nadomestijo s tistimi, ki imajo visok potencial za vrhunske športne dosežke v prihodnosti. Glede na navedene strategije se po agresivnosti nahajajo v sami sredini med naštetimi strateškimi usmeritvami. V svetu profesionalnega športa relativno lahko zaznamo športne klube s takšnim strateškim fokusom, saj je za njih značilno, da skozi daljše obdobje tekmujejo v visoko-kakovostnih tekmovanjih in imajo obenem ugled organizacij z vrhunskimi notranjimi procesi.

(3) Strateški fokus na anorganski rasti organizacije. Gre za najbolj agresivno strategijo izmed vseh naštetih. Ta strategija je značilna za klube, kjer investitorji zahtevajo hitro povračilo vložka, klub pa je osredotočen na vrhunski športni rezultat. Te organizacije stremijo k rasti z vidika povečevanja vrednosti igralske ekipe. V slednjo vlagajo praktično vse svoje presežke, medtem ko na drugih področjih stroške zmanjšujejo. Čeprav je v določenem pogledu lahko sorodna strategiji zasledovanja vrhunskega športnega rezultata, ta usmeritev predstavlja alternativo kontinuiranemu doseganju vrhunskih športnih rezultatov na dolgi rok. Njena temeljna ambicija je hitri preboj med najboljše oziroma želja po čim hitrejšem doseganju pozitivnih spiralnih učinkov. Gre za najbolj tvegano strategijo, ki jo običajno uporabljajo klubi, kateri trenutno ne tekmujejo $\mathrm{v}$ najkakovostnejših tekmovanjih, s svojim obsegom finančnih sredstev pa bistveno presegajo konkurenco $\mathrm{v}$ svojem rangu in si lahko privoščijo zamenjavo celotne ekipe s pridobivanjem novih kakovostnejših športnikov na mednarodnih trgih. Medtem ko se prejšnji pristop zanaša na postopno izboljšanje notranjih procesov, kar vključuje postopno grajenje ekipe s ciljem doseganja večje stopnje zaupanja in kohezivnosti, ta strategija sledi prepričanju, da je za športni rezultat pomembnejša trenutna psiho-fizična in taktična kakovost posameznikov, ki se odraža preko njihove tržne vrednosti. Dražji športniki naj bi torej bili sposobni doseči tudi boljši športni rezultat in so posledično sposobni pomagati klubu pri hitrejšem generiranju presežka prihodkov nad odhodki, vendar pa to ni nujno. Študije namreč kažejo, da vrhunski športni rezultat ne vodi nujno do višjih dobičkov, obenem pa je dobro finančno poslovanje mogoče tudi ob odsotnosti izrednih rezultatov (Kase et al., 2006, str. 7). Poskusi hitrega povečevanja možnosti za vrhunski športni rezultat lahko resno ogrozijo finančno 
stabilnost kluba, zato to strategijo opredeljuje kot tvegano, saj temelji na finančnem vzvodu s kratkoročnimi interesi, kar nasprotuje načelom trajnostne strategije.

(4) Strateški fokus na povečevanju rezerv oziroma na preživetju kluba. Gre za najbolj defenzivno strategijo izmed vseh pet opredeljenih. Ključna odločitev teh klubov je zmanjševanje stroškov. V obdobju gospodarske stagnacije ali celo recesije športni klubi najhitreje občutijo upad sponzorskih in donatorskih sredstev. V takšnem obdobju se zato vse več športnih klubov ukvarja s težavo preživetja, saj obseg razpoložljivih finančnih sredstev pogosto ne zadošča niti za izpolnjevanje osnovnih obveznosti kluba, kot so na primer kotizacija za nastop v določenem tekmovanju, pokrivanje stroškov sojenja, prevoza na tekme itd. Vodstva teh klubov zato poskušajo odložiti vse investicije, ki niso nujne in enostavno poskušajo preživeti težke čase s poravnavanjem dolgov ali ustvarjanjem rezerv zaradi negotovosti glede prihodnjega denarnega toka. Posledično vodstva teh klubov ne angažirajo novih športnikov, v kolikor niso brezplačni. Ti klubi se ne odločajo za fokus na vrhunske športne rezultate, saj običajno odprodajajo pravice, ki jih imajo do najboljših športnikov v svoji ekipi. Obenem se nekoliko bolj usmerjajo na delo z lokalno skupnostjo in si tako poskušajo zagotoviti stalen dotok sredstev iz javnih virov.

(5) Strateški fokus na organski rasti organizacije. Športni klubi, ki zasledujejo strategijo organske rasti, so bolj naklonjeni rasti kot zmanjševanju stroškov, obenem pa stremijo $h$ kontinuirani dolgoročni rasti. Klubsko vodstvo se pri tem namesto vlaganj v člansko športno ekipo in profesionalni del organizacije osredotoča na vlaganje finančnih presežkov v amaterske dele kluba. Osnovni cilj takšnih pristopov ni krepitev tekmovalne ekipe, temveč izboljšava dolgoročnih notranjih procesov in rast organizacije, ki temelji na delu z mladimi. Običajno je ta strateški fokus primeren za športne klube, ki sodelujejo v manj kakovostnih tekmovanjih in nimajo velikih finančnih kapacitet. Vodstvo klubov, ki zasledujejo strategijo organske rasti, je običajno nenaklonjeno tveganju. Ta strateški fokus implicira poskus izboljšave kapacitet organizacijskega menedžmenta, kar naj bi služilo kot izhodišče za povečanje učinkovitosti notranjih procesov. Pri tem je ključnega pomena izboljšanje pogojev za razvoj lastne baze športnikov, ki bi v prihodnosti lahko omogočili doseganje vrhunskih športnih rezultatov. Ravno slednji so običajno v tej strategiji nekoliko bolj poudarjeni od ciljev lokalnega okolja. Želja po rasti in napredovanju v višje kakovostne range uvrščajo ta strateški pristop $\mathrm{v}$ sfero zmerne agresivnosti. Takšni klubi se ob pomanjkanju sponzorskih sredstev večinoma financirajo iz transferjev športnikov, zato včasih veljajo tudi za »izvoznike« talentov. Neredko se tudi zgodi, da so športniki, ki so svojo športno pot začeli ravno $\mathrm{v}$ teh klubih, nadproporcionalno udeleženi $\mathrm{v}$ izbranih nacionalnih vrstah. Število reprezentantov namreč pogosto presega kakovost klubskih rezultatov.

\subsection{Dejanske strateške usmeritve košarkarskih klubov}

Tabela 2 prikazuje rezultate opredeljevanja anketirancev glede strateških usmeritev klubov. Slednje so bile merjene na 7-stopenjski Likertovi lestvici, pri čemer so višje vrednosti 
predstavljale večje poudarjanje rasti od zniževanja stroškov, večje poudarjanje ciljev lokalne skupnosti od športnega rezultata in večje poudarjanje manjšega tveganja od hitrih rezultatov. Iz rezultatov lahko razberemo, da so klubi nižjega ranga dosegali višje vrednosti pri vseh treh postavkah.

Tabela 2. Razlike v strateških usmeritvah med klubi na različnih kakovostnih ravneh

\begin{tabular}{lccc}
\hline $\begin{array}{c}\text { Kakovostna } \\
\text { raven }\end{array}$ & $\begin{array}{c}\text { Pomembnost rasti } \\
\text { organizacije nasproti } \\
\text { zmanjševanju stroškov }\end{array}$ & $\begin{array}{c}\text { Pomembnost razvoja } \\
\text { lokalnega okolja nasproti } \\
\text { vrhunskemu športnemu } \\
\text { rezultatu }\end{array}$ & $\begin{array}{c}\text { Pomembnost dela na } \\
\text { dolgi rok in manjšega } \\
\text { tveganja nasproti hitrim } \\
\text { rezultatom }\end{array}$ \\
\hline ABA liga & 1,78 & 1,56 & 3,22 \\
Prva liga & 3,26 & 3,78 & 4,85 \\
Druga liga & 4,45 & 5,35 & 5,90 \\
Nižje lige & 4,40 & 5,80 & 6,40 \\
Skupaj & 4,00 & 4,86 & 5,62 \\
\hline
\end{tabular}

V nadaljevanju smo preverili še, kako se vplivnost posameznih deležnikov na strateško odločanje v klubih odraža na dejanske strateške odločitve. Pri tem smo vplivnost interesnih skupin merili v skladu s priporočili Ivašković (2019b, str. 1464). Rezultati v tabeli 3 kažejo, da klubi z večjo vplivnostjo prostovoljcev in občinskih oblasti bolj poudarjajo rast, razvoj lokalnega okolja in manjše tveganje, podobna pa sta tudi učinka panožnih zvez in lokalne skupnosti. Nasprotno učinkujejo zasebni sponzorji. Njihov vpliv se namreč odraža na večjem poudarjanju optimizacije stroškov, športnih dosežkov in hitrem uresničevanju ciljev.

Tabela 3. Korelacija vplivnosti interesnih skupin in pomembnosti strateških usmeritev

\begin{tabular}{lccc}
\hline Interesna skupina & $\begin{array}{c}\text { Pomembnost rasti } \\
\text { organizacije v } \\
\text { primerjavi z } \\
\text { zmanjševanjem } \\
\text { stroškov }\end{array}$ & $\begin{array}{c}\text { Pomembnost razvoja } \\
\text { lokalnega okolja v } \\
\text { primerjavi z vrhunskim } \\
\text { sportnim rezultatom }\end{array}$ & $\begin{array}{c}\text { Pomembnost dela } \\
\text { na dolgi rok in } \\
\text { manjšega tveganja v } \\
\text { primerjavi s hitrim } \\
\text { rezultatom }\end{array}$ \\
\hline Občinske oblasti &, $34^{* *}$ &, $48^{* *}$ &, $26^{*}$ \\
Državne oblasti &, 18 &, 11 &,- 10 \\
Mediji &, 11 &, 06 &, 15 \\
Sponzorji &,$- 49^{* *}$ &,$- 34^{* *}$ &,$- 24^{*}$ \\
Košarkarske zveze &, $37^{* *}$ &, $37 * *$ &, 20 \\
Košarkarji in trenerji &,- 22 &,- 10 &,- 16 \\
Zaposleni &,- 04 &,- 10 &, $33^{* *}$ \\
Prostovoljci &, $40^{* *}$ &, $65^{* *}$ &, $39 * *$ \\
Širša javnost &, 01 &,- 04 &, 06 \\
Lokalna skupnost &, 21 &, $40^{* *}$ &, $41^{* *}$ \\
\hline
\end{tabular}

Legenda: ** - $\mathrm{P}<0,01 ; *-\mathrm{P}<0,05$.

Rezultati nas napeljujejo na sklep, da večja vplivnost zasebnih sponzorjev na strateške odločitve košarkarskih klubov potiska te organizacije v smeri fokusa na športnih rezultatih oz. v smeri strategije anorganske rasti. Na drugi strani se večja vplivnost prostovoljcev, občinskih oblasti, košarkarskih zvez in lokalnih skupnosti odraža v bolj pogosti izbiri strategije organske rasti ali strategije razvoja okolja. 


\section{Zaključek}

Prispevek prikazuje strateške alternative, ki so na voljo športnim klubom v (post)tranzicijskih evropskih državah, kateri delujejo na področju ekipnih športov in še vedno ohranjajo status neprofitnih organizacij. Na izbor slednjih vpliva kontekst, $\mathrm{v}$ katerem klubi delujejo, predvsem viri financiranja. $\mathrm{V}$ primerjavi z državami z neprekinjeno tradicijo tržnega gospodarstva so klubi v (post)tranzicijskih državah še vedno nekoliko bolj odvisni od podjetij, medtem ko gospodinjstva prispevajo primerjalno majhen delež v njihove proračune. Poleg tega opazovane športne klube zaznamuje dejstvo, da delujejo v evropskem tekmovalnem sistemu, kjer je večina tekmovanj še vedno odprtega tipa in omogoča tako napredovanje $v$ višje kot nazadovanje $v$ nižje range tekmovanja, obenem pa morajo ob pomanjkanju sodelovanja šolskega in visokošolskega sistema klubi sami skrbeti za razvoj športnih kadrov. V (post)tranzicijskem kontekstu še vedno prevladujejo neprofitne statusne oblike, kar poleg splošnih značilnosti športnih klubov (krajša delovna doba športnikov in posledično relativno razvit trg vrhunskih športnikov) vpliva na mešanje amaterskega in profesionalnega dela znotraj iste organizacije. Ti klubi imajo posledično v svojih organizacijah posebne pogone za mlajše starostne kategorije in dvodelne HRM sisteme. $\mathrm{V}$ okviru tega se pred klubska vodstva postavljajo tri ključne strateške dileme, in sicer:

- Vsebinska dilema: v kolikšni meri poudarjati pomembnost vrhunskih tekmovalnih rezultatov (intenzivno športno delovanje) na račun želje po razvoju lokalne skupnosti (ekstenzivno delovanje)?

- Dilema tveganja: v kolikšni meri zahtevati hitre rezultate (sprejemati večje tveganje) nasproti dolgoročnemu delu in manjšemu tveganju?

- Dilema rasti: v kolikšni meri izpolnjevati cilj zmanjševanja stroškov nasproti ambiciji po rasti organizacije?

Glede na razrešitev teh dilem se klubom ponuja osem kombinacij, v katerih lahko zaznamo pet temeljnih strateških alternativ, in sicer: strategija fokusa na športnih rezultatih, strategija anorganske rasti, strategija organske rasti, strategija razvoja okolja ter strategija povečevanja rezerv oz. preživetja. Klubi z večjo vplivnostjo prostovoljcev in občinskih oblasti bolj poudarjajo rast, razvoj lokalnega okolja in manjše tveganje, podobna pa sta tudi učinka panožnih zvez in lokalne skupnosti. Nasprotno učinkujejo zasebni sponzorji. Na podlagi tega lahko sklepamo, da večja vplivnost zasebnih sponzorjev potiska klube v smeri fokusa na športnih rezultatih oz. v smeri strategije anorganske rasti, medtem ko se večja vplivnost prostovoljcev, občinskih oblasti, košarkarskih zvez in lokalnih skupnosti odraža v bolj pogosti izbiri strategije organske rasti ali strategije razvoja okolja.

Rezultati te študije služijo kot pomoč vodstvom klubov pri lažjem doseganju konsenza znotraj posameznih organizacij pri opredeljevanju in izbiri strateških usmeritev, ki bodo najbolj ustrezala njihovemu poslanstvu. Obenem lahko zakonodajalcu olajšajo odločanje v procesu priprave inštrumentov, ki bodo opredelili diferencirane vloge javnih inštitucij v klubih, ki zasledujejo različne strategije. 


\section{Reference}

1. Andreff, W. (2006). Sport and financing. V: Andreff, W. \& Szymanski, S. (ur.). Handbook on the Economics of Sport. Cheltenham: Edward Elgar, 271-281.

2. Andreff, W., Dutoya, J., \& Montel, J. (2009). A European model of sports financing: under threat? Pridobljeno na https://www.playthegame.org/news/news-articles/2009/a-european-modelof-sports-financing-under-threat/, dostop 5. 5. 2021.

3. Arnaut, J. L. (2006). Independent European Sport Review. Pridobljeno na http://eose.org/wpcontent/uploads/2014/03/independant_european_sports_review1.pdf, obiskano 16. 3. 2021.

4. Barget, E. \& Chavinier-Rela, S. (2017). The analysis of amateur sports clubs funding: A European perspective. Athens Journal of Sports, 4(1), 7-34.

5. Baroncelli, A. \& Lago, U. (2006). Italian Football. Journal of Sport Economics, February, 13-28.

6. Downward, P., Dawson, A. and Dejonghe, T. (2009). Sports Economics: Theory, Evidence and Policy. Oxford: Butterworth-Heinemann.

7. Evropska komisija (2007). Commission staff working document: The EU and sport: background context. Accompanying document to the white paper on sport. Pridobljeno na http://eurlex.europa.eu/legal-content/EN/TXT/?uri=CELEX:52007SC0935, dostop 9. 5. 2021.

8. Fort, R. (2000). European and North American sports differences? Scottish Journal of Political Economy, 47(4), 431-455.

9. Ivašković, I. (2018). Analiza razlik v sistemih ravnanja z ljudmi pri delu v košarkarskih klubih Jugovzhodne Evrope. Šport: revija za teoretična in praktična vprašanja športa, 66(1/2), str. 189195.

10. Ivašković, I. (2019a). Za kaj si prizadevajo neprofitni športni klubi? Economic and business review, 21 (pos. št.), 159-163.

11. Ivašković, I. (2019b). The stakeholder-strategy relationship in non-profit basketball clubs. Economic Research, 32(1), 1457-1475.

12. Ivašković, I. (2020). Učinki javnega financiranja na neprofitna športna društva. Teorija in praksa: revija za družbena vprašanja, 57(2), 664-680.

13. Kase, K., Gómez, S., Urrutia, I., Opazo, M., \& Martí, C. (2006). Real Madrid-Barcelona: business strategy vs. sports strategy, 2000-2006. Occasional Paper, 6(12), str. 1-26.

14. Kern, A., Schwarzmann, M., \& Wiedenegger, A. (2012). Measuring the efficiency of English Premier League football: A two-stage data envelopment analysis approach. Sport, Business and Management: An International Journal, 2(3), 177-195.

15. Ko, W. W. \& Liu, G. (2020). The Transformation from Traditional Nonprofit Organizations to Social Enterprises: An Institutional Entrepreneurship Perspective. Journal of Business Ethics, $v$ tisku. Pridobljeno na https://link.springer.com/article/10.1007/s10551-020-04446-z, dostop 20. 9. 2020.

16. Lange, D. (2020). Share of people who volunteer in sport in the European Union (EU) 2013-17, by country. Statista. Pridobljeno na https://www.statista.com/statistics/602010/european-unionvolunteering-in-sports-by-country/, dostop 20. 12. 2020.

17. Porter, M. E. (1985). Competitive Advantage. New York: Free Press.

18. Porter, M. E. (1987). From Competitive Advantage to Corporate Strategy. Boston: Harvard Business Review. Pridobljeno na https://www.academia.edu/6689159/From_competitive_advantage_to_corporate_strategy, dostop 22. 4. 2021.

19. Pučko, D. (1999). Strateško upravljanje. 2. izdaja. Ljubljana: Ekonomska fakulteta. 
20. Sanchez, L. C., Barajas, A., \& Sanchez-Fernandez, P. (2019). Sport finance: Revenue sources and financial regulations in European football. V: Garcija, J. (ur.). Sports (and) Economics. Madrid: Funcas, str. 327-366.

21. Svet Evrope (2021). European Sports Charter. Pridobljeno na https://www.coe.int/en/web/sport/european-sports-charter, dostop 8. 5. 2021.

22. Škorić, S., Bartoluci, M., \& Čustonja, Z. (2012). Public financing in Croatian sport. Financial Theory \& Practice, 36(2), 109-227.

23. Škorić, S. \& Bartoluci, M. (2014). Planning in the Croatian national sport federations. Kinesiology, 46(Supplement 1), 120-126.

24. Tan, J. \& Litschert, R. J. (1994). Environment-strategy relationship and its performance implications: An empirical study of Chinese electronics industry. Strategic Management Journal, 15(1), 1-20.

25. Zakon o sportu (2019). Pročišćeni tekst NN 98/19. Pridobljeno na https://www.zakon.hr/z/300/Zakon-o-sportu, obiskano 21. 3. 2020.

Igor Ivašković je diplomiral iz prava, zgodovine, južnoslovanskih študijev, pedagogike in andragogike in ekonomije, doktoriral je iz prava, poslovnih ved in politologije ter je trenutno zaposlen na Ekonomski fakulteti Univerze v Ljubljani.

$$
* * *
$$

\section{Abstract: Strategic Dilemmas and Alternatives of Non-Profit Sports Clubs}

Research Question (RQ): What are the key strategic decisions made by sport club management and what strategic alternatives are available to them?

Purpose: The purpose is to help the management of non-profit sport clubs by identifying key strategic dilemmas and their strategic alternatives.

Method: The analysis of economic, political and other social factors that influenced the sports industry was used. Then, a review of the management literature is used for an explanation of the production process specifics and identification of three key strategic dilemmas.

Results: Three dilemmas identified are: a) the focus on sport results vs. the development of the local community, b) quick achievement of goals vs. reducing the level of risk, c) reduction of costs vs. organizational growth. Based on different combinations, the article presents five basic alternative orientations, namely: a) strategic focus on sports results, b) strategy of inorganic growth, c) strategy of organic growth, d) strategy of local community development, and e) strategy of increasing organizational reserves.

Organization: The study offers a new classification of strategies for non-profit sports clubs.

Society: The study emphasizes the importance of the relationship between sports clubs and the local community, and shows how this relationship changes according to the chosen strategy.

Originality: A new classification of strategic alternatives. One of the first surveys on key business decisions of non-profit sports clubs in South-East Europe.

Limitations / further research: Further research between sports clubs over a long period of time, in different environments, and in different sport branches is recommended.

Keywords: sports clubs, non-profit organizations, transition, strategies, business decisions. 
Revija za univerzalno odličnost / Journal of Universal Excellence,

September 2021, leto / year 10, številka / number 3, str. / pp. 250-266.

Copyright (c) Igor IVAŠKOVIĆ

\section{(c) (i) (2)}

Creative Commons License

This work is licensed under a Creative Commons Attribution-ShareAlike 4.0 International License. 